\title{
Retos del Instituto Nacional Electoral en la organización de los procesos internos para la elección de dirigentes partidistas
}

\section{Saúl Mandujano*}

\section{Sumario:}

I. Introducción

II. El carácter democrático en la organización interna de los partidos políticos

III. La intervención de las autoridades electorales en la vida interna de los partidos políticos

IV. El INE y la organización de las elecciones de los dirigentes o dirigencias de los partidos políticos nacionales

V. Aspectos sustantivos respecto a la participación del INE en los procesos de integración de los órganos directivos partidistas

VI. Consideraciones finales

VII. Bibliografía

* Consejero electoral del OPLE Estado de México. 
Esta revista forma parte del acervo de la Biblioteca Jurídica Virtual del Instituto de Investigaciones Jurídicas de la UNAM www.juridicas.unam. $\mathrm{mx}$ 


\section{Introducción}

De acuerdo con la normativa electoral, los partidos políticos cuentan con un amplio margen para autoorganizarse. Esta libertad les permite adoptar la forma más acorde con su ideología. En el mismo sentido, los procesos democráticos internos realizados para elegir a sus candidatos a cargos de elección popular o para renovar a su dirigencia, presentan escenarios muy diversos. Por supuesto, el desarrollo de los procesos internos de selección de candidatos o de elección de las dirigencias partidistas representa una de las dimensiones centrales para evaluar el grado de institucionalización, legitimación y compromiso democrático de esos institutos políticos.

A pesar de lo anterior, un partido político no puede escapar a las exigencias de la vida democrática ni a los imperativos que le señala el sistema jurídico de un Estado, de tal suerte, el margen para autorregularse no es absoluto. En las leyes electorales suele preverse que en sus documentos constitutivos, los partidos deben establecer procedimientos democráticos para la integración y renovación de los órganos directivos, así como las funciones, facultades y obligaciones de los mismos. De no ocurrir así, la autoridad competente podrá negar el registro como partido político a la agrupación que lo haya solicitado, o bien, ordenar modificaciones a los documentos básicos. ${ }^{1}$

Para fortalecer su estructura organizativa y, sobre todo, garantizar los derechos de sus militantes, parece existir una tendencia cada vez mayor a que el Estado intervenga en la vida interna de los partidos. Una mayor injerencia estatal pretende democratizar la vida de estos institutos políticos. Esta tendencia ha roto con el principio clásico de autonomía de los partidos que privilegiaba su libertad para organizarse y desplegar sus idearios y plataformas, dejando al margen al Estado. La relevancia de sus funciones, en tanto entidades de interés público, la complejidad de sus aparatos y el

1 Mediante sentencia dictada en el expediente SUP-JDC-781/2002, la Sala Superior del Tribunal Electoral del Poder Judicial de la Federación confirmó la decisión del Consejo General del Instituto Federal Electoral, en el sentido de negar el registro al Partido Popular Socialista para constituirse como partido político nacional, debido a no advertir en los estatutos los elementos mínimos para ser considerados democráticos. Este asunto dio motivo a la jurisprudencia 3/2005. 
volumen de recursos públicos que administran, ha ido reclamando una mayor regulación de su vida interna por parte del Estado. ${ }^{2}$

En esta misma lógica, la reforma constitucional de 2014 incorporó una nueva forma de injerencia estatal, al prever que, a solicitud de un partido político, el INE organice sus elecciones internas para el relevo de sus dirigencias. Situación delicada, señala el artículo 41 constitucional, fracción $\mathrm{V}$, apartado $\mathrm{B}$, que a petición de los partidos y con cargo a sus prerrogativas, en los términos que establezca la ley, podrá el Instituto Nacional Electoral (INE) organizar la elección de sus dirigentes. Sin precisar su alcance, pues no se establece que se trate de la renovación de los cuadros directivos nacionales, estatales o municipales, la disposición constitucional confiere a los partidos la facultad de encomendar al INE la organización de sus procesos internos para la elección de sus dirigentes.

Hace unos años, con la reforma constitucional electoral de 2007, se manifestó el ánimo de atajar el alcance de algunas decisiones jurisdiccionales, al incorporar en la fracción I del artículo 41 constitucional, una limitación para las autoridades de intervenir en los asuntos internos de los partidos políticos, solo en los términos que señalen la propia Constitución y la ley. Celosos de su régimen interno, los partidos decidieron entonces acotar los pronunciamientos de las autoridades electorales.

Con un matiz diferente, se contempla ahora que los partidos políticos opten por encargar al INE la organización de sus procesos internos para elegir dirigentes. Precepto controvertido, la intervención en los procesos internos de los partidos, aun a petición de parte, puede debilitar y no contribuir a su libertad de autoorganización. Dado que es posible vulnerar su vida interna, la organización de las elecciones de los dirigentes partidistas debía seguir siendo un asunto interno y propio de los partidos políticos. En un régimen constitucional de libertades, el modelo electoral debe procurar la intervención mínima de las autoridades electorales y promover el fortalecimiento de los partidos. ${ }^{3}$

2 Peschard, Jacqueline, "Mayor injerencia de los Estados en los partidos políticos”, El Universal, 12 de mayo de 2014, en: http://www.eluniversalmas.com.mx/editoria les/2014/05/68501.php (consultado el 12 de mayo de 2014).

3 Instituto Federal Electoral, Observaciones a la minuta de reforma política de la Consejera María Marván y los Consejeros Electorales Marco Antonio Baños, Lorenzo Córdova y Benito Nacif presentada a la opinión pública y las Cámara de Diputados y Senadores el pasado 5 de diciembre 2013, Coordinación Nacional de Comunicación Social, núm. 157A, disponible en: http://ife.org.mx/portal/site/ifev2/menuitem.92faac40ea85399517bed91 Od08600a0/?vgnextoid $=a 223672 f 90 c 6 b 310 \mathrm{VgnVCM} 1000000 c 68000 a R C R D$ (consultado el 15 de mayo de 2014). 
Pero partiendo de otra lógica, parece suponerse ahora que la intervención de la autoridad electoral dota de certidumbre y legitimidad al proceso interno de elección de dirigentes partidistas. Depositar en manos de un árbitro externo esa clase de elección, impide favorecer a alguna de las corrientes internas, evita fricciones entre los grupos y candidatos en la contienda o limita que al final se desconozcan los resultados. En suma, a través de la participación del INE se busca darle consistencia, eficacia e imparcialidad a la selección de los cuadros directivos de un partido.

Quizá bajo esa lógica el presidente del Partido de la Revolución Democrática (PRD) señaló que ese instituto político otorga un voto de confianza a la autoridad electoral para asignarle la responsabilidad de un evento interno de enorme relevancia. En este contexto, el 2 de mayo pasado, el PRD presentó una solicitud al INE para que se encargue del proceso de relevo de distintos cargos partidarios a nivel nacional, estatal y municipal, exceptuando a la presidencia y las secretarías generales que serán nombradas por el Consejo Nacional del PRD a través del método directo. ${ }^{4}$

No es sencillo que el INE organice la renovación de los cuadros dirigentes de un partido, el hecho puede generar un severo cuestionamiento de la autoridad por parte de los grupos o ciudadanos inconformes. Lejos de una cultura de apego a las reglas y de la aceptabilidad de la derrota, es factible que esta nueva tarea abra frentes adicionales al Instituto. Cabe destacar que la recién aprobada Ley General de Partidos Políticos (LGPP) tiene imprecisiones en el tema y no establece con claridad las responsabilidades de cada cual. ${ }^{5}$

\section{El carácter democrático en la organización interna de los partidos políticos}

Desde su incorporación al texto constitucional en 1977, se ha reconocido a los partidos políticos la facultad para autoorganizarse, como también es cierto que en la ley se han prescrito las características de su creación, su

4 Peschard, Jacqueline, "Mayor injerencia..., cit.

5 En contra de las dudas razonables por la novedad del experimento, las elecciones internas del PRD del 7 de septiembre de 2014, que por primera vez fueron organizadas por el INE, cumplieron su cometido. Con incidentes menores, se instalaron 8,265 casillas y participaron cerca de 2 millones de militantes previamente registrados. A pesar de ello, sigue siendo un reto de enorme significado para el Instituto las elecciones internas de un partido político. 
filiación, selección de candidatos y elección de dirigentes. Sin embargo, es prudente advertir que cuando el legislador sienta las bases para la organización y funcionamiento de los partidos, lo hace en función de que son entidades de interés público. Por tal motivo, lejos de intervenir en los asuntos internos de dichas organizaciones, el legislador está regulando los derechos fundamentales de asociación y afiliación. ${ }^{6}$

Reflexionar sobre el amplio tema de la vida interna de los partidos nos coloca en la idea de que no es sostenible aceptar partidos no democráticos en un sistema político que sí lo es, o que al menos, aspira a serlo. De ahí que la regulación jurídica obligue a los partidos a un mínimo necesario de democracia interna. Como exigencia de que los partidos rijan su organización y funcionamiento interno mediante reglas que permitan la participación de los afiliados en la gestión y control de los órganos de gobierno, la democracia interna alude al reconocimiento de los derechos y atribuciones de los militantes para materializar su intervención en los órganos de dirección.

En todo Estado constitucional democrático de derecho, un principio básico en la actuación de los partidos políticos sigue siendo el de libertad, incluida la de autoorganización. De hecho, un reto para todo ordenamiento que pretenda regular la democracia interna de los partidos es lograr un equilibrio entre dos principios en apariencia contrapuestos, el derecho de autoorganización y el derecho de participación democrática de los afiliados. Siendo parte del derecho político electoral de asociación, debe preservarse la existencia de un ámbito libre de interferencias en la organización y funcionamiento interno de los partidos políticos. Al mismo tiempo, a diferencia de lo que ocurre con otro tipo de asociaciones, los ordenamientos constitucionales y legales ponen énfasis sobre el límite que ese derecho de auto-organización tiene en el caso de los partidos, consistente en el derecho de los propios afiliados a la participación democrática en su organización y funcionamiento. ${ }^{7}$

Existe amplia coincidencia en torno a la idea de que el funcionamiento interno de los partidos no es suficientemente democrático. Sin ser privativo de nuestro país, es casi irresistible la tendencia oligárquica que se

6 González Oropeza, Manuel y Báez Silva, Carlos, La intervención de los órganos electorales del Estado en la vida interna de los partidos políticos, México, UNAM, Instituto de Investigaciones Jurídicas, 2010, p. 10.

Orozco Henríquez, José de Jesús, La democracia interna de los partidos políticos en Iberoamérica y su garantía jurisdiccional, México, Colección de Cuadernos de Divulgación sobre aspectos doctrinarios de la Justicia Electoral, núm. 7, Tribunal Electoral del Poder Judicial de la Federación, 2004, p. 12. 
da al interior de diversos partidos políticos. Por esa razón, la democracia interna tiene por objeto impedir un eventual déficit democrático o un funcionamiento autocrático que se traduzca en una merma para el mecanismo de representación política y ponga en peligro la correcta operación del Estado democrático. Se trata de una carga a través de la cual se pretende asegurar el efectivo cumplimiento de las funciones que tienen encomendadas. $^{8}$

Casi siempre prevalece la duda sobre el grado en que los órganos del Estado pueden invadir o intervenir en la esfera interna de los partidos a fin de garantizar su funcionamiento democrático. Después de todo, a pesar de su naturaleza como instituciones de interés público, no pierden su carácter asociativo. De ahí que el principio básico de su actuación sigue siendo el de libertad y autoorganización.

Instituciones autónomas conformadas por individuos que libremente han decidido ser militantes, los partidos políticos son agentes que necesitan actuar bajo un principio de libertad hacia adentro y de responsabilidad hacia afuera. Esa libertad supone la posibilidad de que ellos mismos determinen las reglas a que habrán de sujetarse en sus asuntos íntimos, de manera que no es aventurado afirmar que en esa capacidad para auto-regularse radica la clave de su autonomía política. La ausencia de injerencias externas en cuestiones tan centrales como la designación de dirigentes, la postulación de candidatos, la definición de estrategias políticas o la solución de controversias intrapartidistas, es un elemento vital para mantener un adecuado sistema de partidos. Ahora bien, como todo Estado de derecho encuentra su legitimidad en el acatamiento de las leyes y en la existencia de mecanismos institucionales para evitar que determinados agentes gocen de regímenes de excepción, el hecho de que existan entidades del Estado que tengan la función de juzgar la legalidad de los actos de los partidos políticos, no debe entenderse como una intervención arbitraria o indebida, sino como el desarrollo de la función estatal de solucionar disputas cuando algún interesado así lo solicita. ${ }^{9}$

Asegurar que los partidos se sujeten a controles que garanticen el cumplimiento de la ley y de sus propias normas, sin avasallar en el intento su autonomía, implica tomar en cuenta distintas circunstancias, por un lado, propiciar el avance de los partidos fortaleciendo su capacidad de

8 Ibidem, p. 10.

9 Woldenberg, José, "Vida interna de los partidos políticos y fiscalización de los recursos, nuevos retos de la autoridad electoral", Democracia interna y fiscalización. Memoria del IV Congreso Nacional de Tribunales y Salas Estatales Electorales, México, Tribunal Estatal Electoral de Michoacán, 2002, pp. 17 y 18. 
autodeterminarse, por otro, establecer exigencias y mecanismos concretos para evitar que su vida interna se mantenga ausente de controles legales. Es tan necesario asegurar a los partidos su propia autonomía respecto de la injerencia y el interés de cualquier agente externo, como también es indispensable garantizar a los militantes y al electorado en general que hay un grado racional de exigencia legal. ${ }^{10}$

Diversos ordenamientos electorales del país reconocen a los partidos la facultad de autoorganizarse. En su ejercicio tienen la atribución de otorgarse sus documentos básicos: la declaración de principios, el programa de acción y los estatutos. El artículo 23 de la LGPP, numeral 1, inciso $c$, dispone que pueden regular su vida interna y determinar su organización interior y los procedimientos correspondientes. De igual manera, en prácticamente todos los ordenamientos constitucionales y legales, se contempla la adopción de diversos compromisos con los postulados del Estado democrático, los que deben quedar incorporados en sus documentos constitutivos y reflejarse en su actuar cotidiano. Así, el artículo 25 de la LGPP establece que es una obligación de los partidos conducir sus actividades dentro de los cauces legales y ajustar su conducta y la de sus militantes a los principios del Estado democrático.

Definir bases o pautas democráticas a los partidos conlleva límites a su derecho de autoorganización. En la LGPP, artículo 37, se dispone que la declaración de principios contendrá, por lo menos, la obligación de conducir sus actividades por la vía democrática y promover la participación política en igualdad de oportunidades y equidad entre mujeres y hombres. De sentido similar, el artículo 39, previene que los estatutos establecerán las normas y procedimientos democráticos para la integración y renovación de los órganos internos; también las normas y procedimientos democráticos para la postulación de sus candidatos.

De acuerdo con el artículo 34 de la LGPP, los asuntos internos de los partidos políticos comprenden el conjunto de actos y procedimientos re-

10 Flavia Freidenberg, en "Democracia interna: un reto ineludible de los partidos políticos", Revista de Derecho Electoral, San José Costa Rica, núm. 1, primer semestre de 2006, ha expuesto que el creciente descrédito de los partidos ante la opinión pública y las erráticas gestiones de muchos de ellos en contextos de crisis económicas profundas, han llevado a creer que la reforma de los partidos y su democratización interna son centrales para asegurar la estabilidad de la democracia y la gobernabilidad en la región. Sin partidos transparentes, incluyentes y responsables ante sus miembros y ante la sociedad, la distancia entre organizaciones partidistas se incrementa. Por ello, un reto indispensable para mejorar el rendimiento de los sistemas democráticos está en mejorar el funcionamiento interno de los partidos y su manera de vincularse con las instituciones y los ciudadanos, p. 3 . 
lativos a su organización y funcionamiento, con base a lo dispuesto en la Constitución, la propia LGPP, sus estatutos y reglamentos aprobados por los órganos de dirección. De manera enunciativa, son asuntos internos los siguientes:

- La elaboración y modificación de sus documentos básicos, las cuales en ningún caso podrán hacerse una vez iniciado el proceso electoral.

- La determinación de los requisitos y mecanismos para la libre y voluntaria afiliación de los ciudadanos a éstos.

- La elección de los integrantes de sus órganos internos.

- Los procedimientos y requisitos para la selección de sus precandidatos y candidatos a cargos de elección popular.

- Los procesos deliberativos para la definición de sus estrategias políticas y electorales y, en general, para la toma de decisiones por sus órganos internos y de los organismos que agrupen a sus militantes.

- La emisión de los reglamentos internos y acuerdos de carácter general que se requieran para el cumplimiento de sus documentos básicos.

Dejar con frecuencia a los partidos políticos la facultad de autoorganizarse, de regular sus procedimientos democráticos para la selección de sus dirigentes o candidatos a cargos electivos, implica también establecer legalmente algunas bases a las cuales deben ajustar sus estatutos y actos concretos de aplicación. Entre las bases previstas se contempla cierta intervención de la autoridad electoral en la organización de los procedimientos partidarios internos para elegir dirigentes o candidatos, o bien solo se prevé la posibilidad de impugnar ante un órgano jurisdiccional los actos y decisiones respectivos.

Parece adecuada la idea de que la autoridad electoral asuma una eventual intervención en los asuntos suscitados con respecto a los derechos de los militantes. Esta clase de intervención debe tener como objetivo el fortalecimiento de la vida interna de los partidos por la vía de que su propia normatividad se aplique. Cuando intervengan en asuntos partidistas internos, el papel de las autoridades debe acotarse a aquellos casos en donde el partido no sea coherente consigo mismo, en la situación de que no aplique las normas que se ha dado. Dentro de la vida interna de los partidos la misión de la autoridad es velar porque la legalidad que los propios partidos han diseñado sea aplicada por los órganos que, también de manera autónoma, han dispuesto. ${ }^{11}$

11 Woldenberg, José, "Vida interna de los partidos políticos y fiscalización..., cit, pp. 19 y 20. 
Mediante su reconocimiento como entidades de interés público, se advierte en el marco jurídico disposiciones que pretenden el fortalecimiento de los partidos políticos. Así gozan de los derechos y prerrogativas que establecen la Constitución y la ley, pero al mismo tiempo están sujetos a las obligaciones que los citados ordenamientos prevén a su cargo. Por ejemplo, en cuanto a los órganos directivos el legislador determina aquellos que deberán contemplarse. El artículo 43 de la LGPP enuncia que cada partido debe contar cuando menos con los siguientes:

a) Una asamblea u órgano equivalente, integrado con representantes de todas las entidades federativas en el caso de partidos políticos nacionales, o de los municipios en el caso de partidos políticos locales, la cual será la máxima autoridad del partido y tendrá facultades deliberativas.

b) Un comité nacional o local u órgano equivalente, para los partidos políticos, según corresponda, que será el representante del partido, con facultades ejecutivas, de supervisión y, en su caso, de autorización en las decisiones de las demás instancias partidistas.

c) Un órgano responsable de la administración de su patrimonio y recursos financieros y de la presentación de los informes de ingresos y egresos trimestrales y anuales, de precampaña y campaña.

d) Un órgano de decisión colegiada, democráticamente integrado, responsable de la organización de los procesos para la integración de los órganos internos del partido político y para la selección de candidatos a cargos de elección popular.

e) Un órgano de decisión colegiada, responsable de la impartición de justicia intrapartidaria, el cual deberá ser independiente, imparcial y objetivo.

f) Un órgano encargado de cumplir con las obligaciones de transparencia y acceso a la información que la Constitución y las leyes de la materia imponen a los partidos políticos.

g) Un órgano encargado de la educación y capacitación cívica de los militantes y dirigentes.

Además de los señalados, deberán contar con comités o equivalentes en las entidades federativas con facultades ejecutivas. No parece discutible que la propia Constitución y la ley electoral imponga a los partidos parte de su estructura interna, exigiendo que su funcionamiento sea democrático. Como tampoco es debatible la existencia de un derecho a la tutela judicial completa y efectiva de los derechos fundamentales que corres- 
ponde a sus afiliados, en ese sentido, es correcta la protección que se ofrece a los militantes de intervenir en los procedimientos de selección de los dirigentes partidarios.

Obligados a conducir sus actividades por medios pacíficos y democráticos, cada partido político debe autorregularse mediante la expedición de su normativa interna, pero esa libertad no es absoluta porque además de los parámetros previstos en la ley, deben observarse los elementos mínimos que las autoridades electorales han señalado para que sus documentos constitutivos puedan considerarse democráticos.

\section{La intervención de las autoridades electorales en la vida interna de los partidos políticos}

Corresponde a cada partido político, y solo a él, establecer su propia regulación interna, es precisamente aquí donde radica gran parte de su autonomía. También es conveniente que los conflictos o diferendos al interior de éstos se ventilen y resuelvan por los órganos y mecanismos que cada fuerza política diseñe. El principio a seguir debiera ser el pleno respeto a las determinaciones de los partidos, y solo agotada la instancia interna, a petición expresa, la intervención de las autoridades.

Afirmar lo anterior no significa que las autoridades electorales no puedan verificar la actuación de los órganos partidarios y de sus militantes o simpatizantes. Si las organizaciones políticas se dan unas reglas, la primera obligación es que sean acordes con los postulados del Estado democrático y que se cumplan. Cuando el militante aprecie que han sido ignoradas podrá, tras agotar la instancia interna del propio partido, ejercer una acción ante las autoridades electorales competentes. No es debatible que los tribunales, según la competencia asignada, puedan comprobar si la actuación de los órganos partidarios es conforme a la Constitución, a sus propios instrumentos constitutivos o a la ley.

Al menos en nuestro país, los partidos políticos no son órganos estatales ni asociaciones privadas, son asociaciones políticas de carácter intermedio entre los ciudadanos titulares de los derechos fundamentales de carácter político y los órganos públicos, con el fin de promover la participación del pueblo en la vida democrática, contribuir a la representación nacional y, como organizaciones de ciudadanos, posibilitar el acceso de éstos al ejercicio del poder público. Es decir, no tienen el carácter de órganos del Estado, pero tampoco tienen un estatus de entidad privada. 
Precisamente por ello, de acuerdo con la Constitución y la ley, la vida interna de los partidos está regida por los principios democráticos y es una obligación conducir sus actividades conforme al principio de juridicidad, y ajustar su conducta y la de sus militantes a los principios del Estado constitucional democrático de derecho. ${ }^{12}$

Una de las finalidades de la función electoral de organizar las elecciones, consiste en asegurar de manera integral y directa el ejercicio de los derechos político electorales del ciudadano, comprendiendo todos los aspectos y las medidas dirigidas a ese fin. Con base en esa clase de disposiciones, las autoridades electorales tienen atribuciones para conocer de las infracciones consistentes en el incumplimiento de las obligaciones a cargo de un partido político. Por varios años, la Sala Superior del TEPJF, en su camino a la tutela efectiva de los derechos de los militantes, ha sostenido que los partidos están comprometidos a acatar, de forma escrupulosa, su propia normativa interna, la Constitución y la ley. En caso contrario, la autoridad administrativa tiene facultades sancionadoras. ${ }^{13}$

De acuerdo con el sistema de competencias que se establece en el orden jurídico nacional, tanto el INE como el TEPJF están facultados para intervenir en los asuntos internos de los partidos en los términos que señalen la Constitución y la ley. Tema abordado desde hace algunos años por la Sala Superior del TEPJF, en distintas sentencias precisó que el Consejo General del entonces IFE sí tenía competencia para tutelar las prerrogativas ciudadanas. Con base en una interpretación gramatical y sistemática de la normativa constitucional y legal, dado que el Consejo General del IFE estaba facultado para vigilar que los partidos cumplan con las obligaciones a las que están sujetos, una de las cuales es la observación puntual de sus propios estatutos, dicho instituto se encontraba comprometido a reparar las violaciones de los derechos de los militantes

12 Maitret Hernández, Armando, Democracia interna de los partidos. Obligación de todo órgano partidista a dar respuesta a los militantes, México, Serie Comentarios a las sentencias del Tribunal Electoral, núm. 25, Tribunal Electoral del Poder Judicial de la Federación, 2010, pp. 36 y 37.

13 Desde el precedente SUP-RAP-033/2000, emitido por la Sala Superior del Tribunal Electoral del Poder Judicial de la Federación se prescribió que el Consejo General del Instituto Federal Electoral, tiene atribuciones para conocer de las infracciones imputables a los partidos políticos y, en esa medida, con la suficiente cobertura legal, imponer las sanciones que en derecho correspondan. En forma posterior, el TEPJF ha continuado esbozando que la violación a la normativa partidaria, cuando afecte algún derecho fundamental de los ciudadanos o contravenga una norma de orden público, es susceptible de sancionarse. 
partidistas. La Sala Superior del TEPJF afirmó que si un partido político incumplía con su deber jurídico de respetar el derecho genérico de asociación y el específico de afiliación, el IFE debía dictar las medidas necesarias para restituir al ciudadano ofendido el uso y goce del derecho político-electoral violado.

En estricto sentido, el hecho de vigilar el comportamiento de los partidos no puede considerarse una intervención en su vida interna, pues de esa manera no se les impone una forma de pensamiento o de acción definida, sino el cumplimiento de una norma electoral. Si los partidos gozan de los derechos y las prerrogativas que establecen la Constitución y la ley, a la vez están sujetos a las obligaciones que esos ordenamientos les imponen. Mandar y exigir que los partidos respeten los derechos de los ciudadanos no representa, en esencia, un acto de intervención en su vida interna.

Facultadas para ser vigilantes y garantes del respeto irrestricto a los derechos de los militantes, las autoridades electorales tienen la atribución de analizar la constitucionalidad y legalidad de los estatutos de un partido político. El ejercicio de esta facultad puede llevarse a cabo en tres momentos:

- Al aprobar la solicitud del registro correspondiente como partido político.

- Al aprobar las modificaciones que al estatuto le sean incorporadas.

- Cuando la autoridad electoral emita un acto o resolución, cuyo contenido o sentido reconozca, como base de fundamentación, a las normas estatutarias que se consideran inconstitucionales o ilegales, o fueran efecto o consecuencia directa de ellas, es decir, al aplicar las normas estatutarias a un caso concreto. ${ }^{14}$

Ya sea en los dos primeros supuestos de análisis que corresponden a la autoridad administrativa, o en el tercero, que toca a la autoridad jurisdiccional, es factible determinar si los estatutos contienen los elementos mínimos para declararse constitucionales, entre ellos, que el control de los órganos partidistas permita la posibilidad real y efectiva de que los militantes intervengan en su elección. ${ }^{15}$

14 González Oropeza, Manuel y Báez Silva, Carlos, La intervención de los órganos..., cit., p. 10.

15 Mediante sentencia dictada en el expediente SUP-JDC-1728/2006, la Sala Superior del Tribunal Electoral del Poder Judicial de la Federación determinó que los Estatutos 
De ser así, en la integración y renovación de los órganos directivos deben contemplarse dos aspectos elementales: el establecimiento de aquellos órganos directivos mínimos con los que cada partido debe contar y el establecimiento de mecanismos de control de los órganos directivos. En este segundo tópico debe preverse: la fijación de periodos determinados de duración de los distintos cargos directivos; la previsión de las causas de incompatibilidad entre los distintos cargos al interior del partido y también respecto a cargos públicos; la posibilidad de que los afiliados revoquen el nombramiento conferido a los dirigentes del partido, por faltas graves o inadecuada gestión.

Parte esencial del razonamiento para incluir en los estatutos de los partidos la exigencia legal de contemplar no solo los procedimientos o métodos de elección y renovación de las dirigencias partidistas, sino que dichos procedimientos deben ser democráticos, es el elemento común relativo a la deliberación y participación de los militantes en los procesos de toma de decisiones. Se trata de considerar la posibilidad real y efectiva de elegir a los titulares de los órganos directivos y removerlos en caso de faltas graves. Es decir, son elementos esenciales de referencia que no basta llevarlos al interior de los partidos políticos, sino que es necesario adaptarlos a su naturaleza a fin de que les permitan cumplir sus finalidades constitucionales.

Estatutos de los partidos políticos. Elementos Mínimos PARA CONSIDERARLOS DEMOCRÁTICOS. El artículo 27, apartado 1, incisos c) y g), del Código Federal de Instituciones y Procedimientos Electorales, impone a los partidos políticos la obligación de establecer en sus estatutos, procedimientos democráticos para la integración y renovación de los órganos directivos; sin embargo, no define este concepto, ni proporciona elementos suficientes para

del Partido Acción Nacional, artículo 94, al conferir facultades discrecionales al Comité Ejecutivo Nacional para designar un delegación que sustituya a un comité estatal, violan los principios democráticos de legalidad y certeza jurídica previstos en el artículo 41 constitucional, pues el precepto no esclarece cuáles son los parámetros para clarificar los acontecimientos necesarios en el ejercicio de facultades discrecionales. De la misma manera, en sentencias posteriores, el TEPJF se ha pronunciado sobre la inconstitucionalidad de preceptos estatutarios como en el caso del Partido de la Revolución Democrática. En el precedente SUP-RAP-40/2004 la Sala Superior confirmó la decisión del IFE de no registrar, por inconstitucional, la modificación a los estatutos que incluían como requisito para ser candidato interno el de "no ser cónyuge, concubino o pariente consanguíneo, por afinidad, en línea recta u horizontal hasta el segundo grado, de los titulares en ejercicio de los cargos de elección popular que aspira a suceder". 
integrarlo jurídicamente, por lo que es necesario acudir a otras fuentes para precisar los elementos mínimos que deben concurrir en la democracia; los que no se pueden obtener de su uso lingüístico, que comúnmente se refiere a la democracia como un sistema o forma de gobierno o doctrina política favorable a la intervención del pueblo en el gobierno, por lo que es necesario acudir a la doctrina de mayor aceptación, conforme a la cual, es posible desprender, como elementos comunes característicos de la democracia a los siguientes: 1. La deliberación y participación de los ciudadanos, en el mayor grado posible, en los procesos de toma de decisiones, para que respondan lo más fielmente posible a la voluntad popular; 2. Igualdad, para que cada ciudadano participe con igual peso respecto de otro; 3 . Garantía de ciertos derechos fundamentales, principalmente, de libertades de expresión, información y asociación, y 4 . Control de órganos electos, que implica la posibilidad real y efectiva de que los ciudadanos puedan elegir a los titulares del gobierno, y de removerlos en los casos que la gravedad de sus acciones lo amerite. Estos elementos coinciden con los rasgos y características establecidos en la Constitución Política de los Estados Unidos Mexicanos, que recoge la decisión de la voluntad soberana del pueblo de adoptar para el Estado mexicano, la forma de gobierno democrática, pues contempla la participación de los ciudadanos en las decisiones fundamentales, la igualdad de éstos en el ejercicio de sus derechos, los instrumentos para garantizar el respeto de los derechos fundamentales y, finalmente, la posibilidad de controlar a los órganos electos con motivo de sus funciones. Ahora bien, los elementos esenciales de referencia no deben llevarse, sin más, al interior de los partidos políticos, sino que es necesario adaptarlos a su naturaleza, a fin de que no les impidan cumplir sus finalidades constitucionales. De lo anterior, se tiene que los elementos mínimos de democracia que deben estar presentes en los partidos políticos son, conforme al artículo 27, apartado 1, incisos b), c) y g) del código electoral federal, los siguientes: 1 . La asamblea u órgano equivalente, como principal centro decisor del partido, que deberá conformarse con todos los afiliados, o cuando no sea posible, de un gran número de delegados o representantes, debiéndose establecer las formalidades para convocarla, tanto ordinariamente por los órganos de dirección, como extraordinariamente por un número razonable de miembros, la periodicidad con la que se reunirá ordinariamente, así como el quórum necesario para que sesione válidamente; 2 . La protección de los derechos fundamentales de los afiliados, que garanticen el mayor grado de participación posible, como son el voto activo y pasivo en condiciones de igualdad, el derecho a la información, libertad de expresión, libre acceso y salida de los afiliados del partido; 3 . El establecimiento de procedimientos disciplinarios, con las garantías procesales mínimas, como un procedimiento 
previamente establecido, derecho de audiencia y defensa, la tipificación de las irregularidades así como la proporcionalidad en las sanciones, motivación en la determinación o resolución respectiva y competencia a órganos sancionadores, a quienes se asegure independencia e imparcialidad; 4. La existencia de procedimientos de elección donde se garanticen la igualdad en el derecho a elegir dirigentes y candidatos, así como la posibilidad de ser elegidos como tales, que pueden realizarse mediante el voto directo de los afiliados, o indirecto, pudiendo ser secreto o abierto, siempre que el procedimiento garantice el valor de la libertad en la emisión del sufragio; 5. Adopción de la regla de mayoría como criterio básico para la toma de decisiones dentro del partido, a fin de que, con la participación de un número importante o considerable de miembros, puedan tomarse decisiones con efectos vinculantes, sin que se exija la aprobación por mayorías muy elevadas, excepto las de especial trascendencia, y 6. Mecanismos de control de poder, como por ejemplo: la posibilidad de revocar a los dirigentes del partido, el endurecimiento de causas de incompatibilidad entre los distintos cargos dentro del partido o públicos y establecimiento de períodos cortos de mandato. ${ }^{16}$

Exigir la participación de los afiliados en la toma de decisiones tiene como objetivo que éstas emanen de un proceso interno que vaya de abajo hacia arriba, es decir, de las bases del partido a los órganos dirigentes, y no al revés. Este tipo de reglas comprende, además del derecho al sufragio activo y pasivo en la elección de cargos directivos, la garantía de construcción de corrientes dentro del partido, la ampliación sucesiva del carácter representativo y electivo de los órganos decisores, la adopción de la regla de la mayoría como criterio básico para la toma de decisiones, el fomento de instrumentos de democracia directa y el pluralismo al interior del partido. ${ }^{17}$

Sin cuestionar el amplio margen para autoorganizarse, queda claro que la libertad de los partidos no es absoluta, además de los parámetros previstos en la ley, en la jurisprudencia del TEPJF se han establecido aspectos mínimos que deben contemplarse en los estatutos para considerarlos democráticos. En ese sentido, no solo cabe ejercer un control jurisdiccional indirecto de los actos internos para asegurar su apego al principio democrático, sino un control directo mediante la impugnación

${ }_{16}$ Jurisprudencia 3/2005, Jurisprudencia y Tesis Relevantes 1997-2005. Compilación Oficial, México, Tribunal Electoral del Poder Judicial de la Federación, Tercera Época, pp. 120-122.

17 Castillo González, Leonel, Los derechos de la militancia partidista y la jurisdicción, México, Tribunal Electoral del Poder Judicial de la Federación, 2004, pp. 39 y 40. 
que se haga de un acto partidario que se estime violatorio de los derechos político electorales de sus afiliados.

Ahora bien, aun cuando el derecho de autoorganización tiene un límite consistente en el derecho de los propios afiliados a la participación democrática en su organización y funcionamiento, esa misma libertad de autorregularse permite que en los procesos internos para renovar a sus dirigentes partidistas se presenten escenarios muy diversos.

\section{El INE y la organización de las elecciones de los dirigentes o dirigencias de los partidos políticos nacionales}

Según lo establece la Ley General de Partidos Políticos (LGPP), artículo 43, párrafo primero, inciso $d$, entre los órganos internos de los partidos debe contemplarse un órgano de decisión colegiada, electo democráticamente, responsable de organizar los procesos para la integración de los órganos internos del partido político y para la selección de candidatos a cargos de elección popular.

El desarrollo de los procesos relativos a la elección de dirigentes y la selección de candidatos a cargos de representación popular representa una de las dimensiones centrales para evaluar el talante democrático de los partidos y el grado de legitimidad, institucionalización y desempeño. Si bien la tendencia existente dentro de los partidos se ha visto orientada a considerar la apertura y aplicación de convocatorias para permitir la competencia interna, éstas no son suficientes para impedir la presencia de decisiones cupulares que esquivan compromisos de esa naturaleza. Quizás por la preocupación de contener el deseo de ciertas dirigencias partidistas de entorpecer el acceso al poder a grupos o fracciones opositores, se justifica incorporar a la reforma electoral de 2014 la posibilidad de encomendar al INE los procesos de integración de los órganos internos partidistas.

Según lo dispone el artículo 45 de la LGPP, los partidos políticos podrán solicitar al INE que organice la elección de sus órganos de dirección, con base en sus estatutos, reglamentos y procedimientos, y con cargo a sus prerrogativas. Esta clase de solicitud solo podrá presentarse durante periodos no electorales. El partido solicitante acordará con el Instituto los alcances de su participación, así como las condiciones para la organización y desarrollo del proceso, las cuales deberán apegarse a lo establecido en los estatutos y reglamentos partidarios. 
A través del órgano interno facultado estatutariamente, el partido presentará al INE la solicitud de apoyo cuatro meses antes del vencimiento del plazo para la elección del órgano de dirección que corresponda. Si debido a controversias planteadas jurisdiccionalmente el plazo de renovación de un órgano directivo hubiere vencido, el partido podrá solicitar que se organice la elección fuera del plazo señalado. ${ }^{18}$

Se establecerán en el acuerdo respectivo los mecanismos para que los costos de organización del proceso sean con cargo a las prerrogativas del partido solicitante. Está prevista en la LGPP una coordinación con el órgano partidista correspondiente, de ahí que podrá incluirse la eventual contratación por obra determinada de personal del INE para tal fin, es decir, es factible encomendar al Instituto desarrollar solo ciertas etapas del proceso de renovación de los órganos partidistas. Cita la LGPP que la elección se realizará de manera preferente con el apoyo de medios electrónicos para la recepción de la votación.

Conferida la facultad al Consejo General del INE, artículo 44, numeral 1, inciso $f f$ de la LGIPE, para dictar los acuerdos necesarios relativos a organizar las elecciones de las dirigencias de los partidos políticos que así lo soliciten, en sesión pública celebrada el 20 de junio de 2014, se aprobaron los Lineamientos del Instituto Nacional Electoral para la Organización de las Elecciones de los Dirigentes o Dirigencias de los Partidos Políticos Nacionales a Través del Voto Universal y Directo de sus Militantes. En principio, este instrumento se refiere solo a la elección mediante el voto universal y directo de sus militantes, quedando fuera de su ámbito de aplicación otras modalidades estatutarias.

Aquello no previsto en los Lineamientos podrá ser materia del Convenio General que celebren el Instituto y el partido político, instrumento a través del cual se acuerdan los alcances de participación en el proceso electivo, así como las condiciones para la organización y desarrollo de dicho proceso, las que deben apegarse a lo previsto en los estatutos y reglamentos del partido político. Es decir, sin pasar por alto la libertad de autoorganización que tienen reconocida. Es en este convenio en el que se determinan los costos derivados de la organización del proceso.

18 Como consta en el antecedente 7 del Convenio de Colaboración que celebran el Instituto Nacional Electoral y el Partido de la Revolución Democrática, fueron designados como representantes encargados de presentar la petición para organizar la elección interna de los cargos partidarios, los CC. José de Jesús Zambrano Grijalva y Alejandro Sánchez Camacho, en su carácter de presidente nacional y secretario general nacional del PRD. 
Considerada una responsabilidad compartida, descrito en el artículo 2o., fracción III, inciso $g$, de los Lineamientos, el proceso electivo o proceso para las elecciones de los dirigentes o dirigencias partidistas, es un conjunto de actos realizados por la autoridad electoral, los partidos políticos, sus afiliados o militantes y los ciudadanos que intervienen en él, con el propósito de renovar o decidir la integración de los órganos internos de dirección. Esta clase de actos se rigen por lo dispuesto en la Constitución, la LGPP, el Convenio General, los estatutos, reglamentos y procedimientos de los partidos políticos. Como parte de la normativa aplicable, también rige el Acuerdo General, aquel instrumento mediante el cual el Consejo General del INE aprueba el dictamen de posibilidad o imposibilidad material de organizar las elecciones de las dirigencias que el partido solicitó. ${ }^{19}$

Si ocurre algo no previsto en los lineamientos, el supuesto será resuelto por el Consejo General o, en su caso, por la Comisión de Prerrogativas y Partidos Políticos del INE (Comisión) en sus respectivos ámbitos de competencia. En todo caso debe tomarse en cuenta la libertad de decisión interna de los partidos y el ejercicio de los derechos de sus afiliados y militantes. De llegar a existir incompatibilidad entre las disposiciones aplicables, el Consejo General o la Comisión habrán de elegir la que tutele de mejor forma los derechos de los afiliados y militantes. Se trata de realizar una interpretación armónica que permita salvaguardar los derechos políticos reconocidos.

Conforme la modalidad de votación prevista en los lineamientos, además del Consejo General, una parte sustantiva de la estructura del INE se ve involucrada. La Comisión de Capacitación Electoral y Educación Cívica, Comisión de Prerrogativas y Partidos Políticos, Comisión del Registro Federal de Electores, Dirección Ejecutiva de Capacitación Electoral y Educación Cívica, Dirección Ejecutiva de Organización Electoral,

19 Con base en el Acuerdo INE/CG86/2014, de fecha 2 de julio de 2014, el Consejo General del INE dictaminó la posibilidad material para organizar la elección nacional de integrantes del Consejo Nacional, Consejos Estatales y Municipales y Congreso Nacional del Partido de la Revolución Democrática. En el Acuerdo se considera que el instituto tiene la experiencia y estructura requerida para la organización y desarrollo de los trabajos de capacitación, organización, validación de la lista de electores y cómputo de votos, entre otros. Se sostiene en el Acuerdo que una vez analizado las implicaciones técnicas, materiales y jurídicas que trae consigo la petición hecha por el PRD, no se advierte la existencia de impedimentos para llevarla a cabo, en los términos y plazos del Convenio de Colaboración suscrito. En el Acuerdo se manifiesta que la colaboración del INE en la realización de los comicios internos del Partido de la Revolución Democrática no transgrede en absoluto su vida interna. 
Dirección Ejecutiva del Registro Federal de Electores, Unidad Técnica de Servicios de Informática, la Junta General Ejecutiva y las juntas locales y distritales ejecutivas.

De regreso al procedimiento, mediante escrito del órgano facultado para ello, la solicitud para organizar la elección de dirigentes o dirigencias de los partidos deberá presentarse ante la Dirección Ejecutiva de Prerrogativas y Partidos Políticos, acompañado del fundamento estatutario y copia certificada del acuerdo adoptado por el órgano competente. En términos de lo indicado en el artículo 9o. de los Lineamientos, deberá integrarse la documentación e información siguiente:

a) La lista de los electores que participarán en el proceso electivo de referencia, misma que deberá estar capturada en el sistema de registro que para tal efecto determine el Instituto, incluyendo los datos actuales de todos los afiliados o militantes contenidos en las mismas, consistentes en: apellido paterno, materno y nombre; género y, en su caso, clave de elector.

b) Cada uno de los cargos de dirigentes o dirigencias a elegir, el número de los mismos, el método y modalidades de la elección conforme a su normatividad interna.

c) El nombre o denominación de cada tipo de elección, conforme a lo establecido en su normatividad interna.

d) Conforme a la lista de electores y en términos de su normatividad interna, las entidades, distritos, municipios y/o delegaciones, en los que se efectuará la elección, y

e) Una propuesta de calendario para la realización del o los procesos electivos, de conformidad con estos lineamientos.

Una vez recibida la solicitud y, en su caso, observadas las previsiones que se hubieren hecho, la Dirección Ejecutiva de Prerrogativas y Partidos Políticos elaborará un proyecto de Acuerdo General y, si procede, un proyecto de Convenio General que deberán ser aprobados por el Consejo General del Instituto en un plazo no mayor de 30 días naturales, contados a partir de la presentación de la solicitud o de la fecha en que venza el plazo conferido para subsanar las aclaraciones. Podrá el INE declarar la imposibilidad material de realizar el proceso de elección cuando la solicitud no se apegue a lo dispuesto en la LGIPE, la LGPP y los lineamientos; o por cualquier otra causa fundada y motivada. Por ejemplo, si la petición es extemporánea o no se solicita por el órgano facultado para ello. También es probable que el motivo sea la falta de acuerdo en el costo de la actividad a cargo del instituto. 
En ningún caso se emplearán recursos del INE para la organización y desarrollo del proceso electivo acordado. A petición de la Dirección Ejecutiva de Prerrogativas y Partidos Políticos corresponde a la Dirección Ejecutiva de Administración aplicar los descuentos correspondientes en las ministraciones del partido político solicitante, en términos de lo acordado en el Convenio respectivo. Los descuentos se aplicarán a partir de la ministración siguiente a la firma del convenio y de acuerdo a los plazos que para la erogación se hubieren establecido.

Con base en lo dispuesto por la normativa aplicable, todo Convenio General debe especificar, al menos, las responsabilidades y los mecanismos de coordinación entre el instituto y el partido político en la organización y desarrollo del proceso electivo. Se establecerá el calendario de las actividades del proceso, la fecha y condiciones de la terminación, así como las causales de rescisión del propio convenio. A partir de la modalidad de elección prevista en los Lineamientos, también se pacta lo concerniente a la producción y características de la documentación y materiales electorales.

Es facultad del partido político emitir la Convocatoria acorde a lo establecido en su normativa interna, así como en el Acuerdo y convenios generales aprobados por el Consejo General del INE. Los requisitos de elegibilidad de los candidatos deben estar previstos en las disposiciones que rigen la vida interna del partido. El artículo 29 de los Lineamientos permite que el registro de candidatos se realiza por el partido político o el instituto, según lo acordado en el Convenio. Es factible la sustitución de los candidatos registrados de conformidad con los plazos y condiciones señaladas en las normas estatutarias. Si así sucede, la sustitución debe notificarse a la Dirección Ejecutiva de Prerrogativas y Partidos Políticos en un plazo no mayor a 24 horas contadas a partir de que ocurra. De estar impresas ya las boletas, no se modificarán y los resultados serán válidos para las nuevas candidaturas.

Respecto a la parte operativa del proceso electivo, se replica en gran medida lo previsto en la LGIPE para el proceso electoral. Considerando que el mecanismo de elección es a través del voto universal y directo de la militancia, son sustantivos los aspectos relacionados con: el número y ubicación de las casillas; la integración de las mesas receptoras; el registro de representantes; la documentación y material electoral; la votación y el cómputo final.

Acordado por la Comisión, a partir de la propuesta formulada por el partido político, el número y ubicación de casillas se determinará en función de la cantidad de militantes y afiliados, tomando como base el 
tipo de elección y la lista definitiva de electores que será utilizada para el proceso electivo. Es responsabilidad del partido presentar la lista de ciudadanos electores, misma que después de la depuración y verificación pertinente a cargo de la Dirección Ejecutiva del Registro Federal de Electores, será aprobada por la Comisión.

Integradas por un presidente, un secretario, un escrutador y dos suplentes generales, el procedimiento para la integración de las mesas receptoras estará a cargo de la Dirección Ejecutiva de Capacitación Electoral y Educación Cívica. A fin de garantizar el número suficiente de militantes o afiliados para la integración de las mesas receptoras, dependiendo del número de casillas a instalar, la Comisión determinará el porcentaje de militantes requerido y los criterios de selección aleatoria. Se ordenará la publicación de las listas de ubicación de las mesas receptoras y los nombres de quienes las integran, por lo menos cinco días previos a la jornada electiva y en los términos señalados por el Convenio General.

Acorde a los principios que rigen la función electoral, de manera particular los relativos a velar por la legalidad y certeza del proceso electivo, los candidatos podrán acreditar a un representante ante cada Junta Local y Distrital Ejecutiva, según corresponda, de acuerdo con el cargo por el que contienden. Los términos de dichas representaciones se ajustarán a lo previsto en el Convenio General. Del mismo modo, los candidatos podrán acreditar a un representante ante las mesas receptoras.

El día de la jornada electoral, los militantes o afiliados designados como presidente, secretario y escrutador, en presencia de los representantes de los candidatos, procederán a la instalación de la mesa receptora en el lugar previamente aprobado por la Comisión. De darse la ausencia de uno o alguno de los integrantes de las mesas, el personal designado por la Junta Ejecutiva que corresponda tomará las medidas necesarias y procederá a la instalación, incorporando electores que se encuentren en la fila para votar y reúnan los requisitos exigidos. Instalada la mesa iniciará la recepción de la votación.

Iniciada la votación, a partir de las 8:00 horas, no podrá suspenderse salvo por caso fortuito o causa de fuerza mayor. En tal supuesto, el presidente dará inmediato aviso al funcionario designado por la Junta correspondiente, quien deberá asentar la hora y las causas de la suspensión, indicando a los votantes la determinación. Es facultad de la Junta Ejecutiva tomar las medidas pertinentes para superar la causa y, si procede, decidir si existen condiciones para reanudar la votación.

Concluido el escrutinio y cómputo de casilla, se integrará el expediente de votación. Pudiendo acompañarse de los representantes de los can- 
didatos, es responsabilidad del presidente de la mesa entregarlo de manera inmediata en la sede de las juntas distritales ejecutivas. De acuerdo al artículo 51 de los Lineamientos, podrá el partido político solicitar al Instituto que se encargue del traslado y entrega del expediente, en términos de lo dispuesto en el Convenio General.

Con base en las disposiciones estatutarias del partido político, del Acuerdo y convenios generales, la Comisión aprobará los diseños de la documentación electoral y determinará los materiales e instrumentos que se utilizarán en el proceso electivo. El Instituto podrá convenir la utilización del material electoral de su propiedad para celebrar la jornada electoral.

Lograr la legitimidad de los resultados es pieza clave de todo proceso electivo, es precisamente este aspecto el que justifica la participación del INE en la elección de dirigentes partidistas. Por esa razón, el cómputo de los votos sale del ámbito de competencia de los partidos y entra al del Instituto. Dispuesto en el artículo 53 de los Lineamientos, la Comisión facultará a las juntas distritales ejecutivas, o en su caso, a las juntas locales ejecutivas a realizar el cómputo de la elección, es decir, la suma de los resultados anotados en las actas de escrutinio y cómputo de las mesas receptoras que fueron instaladas en su ámbito territorial. En la sesión de cómputo pueden asistir los representantes de los candidatos.

Realizados los cómputos por las juntas locales y distritales ejecutivas, el secretario de la Junta General Ejecutiva integrará el expediente electoral con los originales de las actas certificadas de los cómputos, los cuales remitirá al presidente de la Comisión, conservando una copia certificada de la documentación. El cómputo total de la elección lo lleva a cabo la Junta General Ejecutiva y lo remite a la Comisión para integrar el informe final que ésta presentará al Consejo General del Instituto. El presidente del Consejo General, como presidente de la Junta General Ejecutiva, procederá a expedir los resultados de los cómputos totales de cada una de las elecciones, en los que se precisarán los candidatos que por sí mismos hayan obtenido el mayor número de votos. Los resultados del cómputo total de las respectivas elecciones se harán públicos y serán entregados al partido político solicitante, para los efectos previstos en su normativa interna. Al término del proceso electivo, el Instituto rendirá un informe al partido político en el que se dé cuenta del ejercicio de las prerrogativas. ${ }^{20}$

20 A través del Acuerdo INE/JGE57/2014, del 19 de septiembre de 2014, emitido en sesión extraordinaria por la Junta General Ejecutiva, una vez realizado el cómputo nacional de la elección de consejeros nacionales y de congresistas nacionales del Partido de 
No se omite en los Lineamientos hacer mención que los procesos electivos pueden suscitar controversias. De ser así, los afiliados, militantes o candidatos del partido solicitante podrán ejercer los medios de defensa previstos en las disposiciones estatutarias y reglamentarias del propio partido político, en caso de estimar que los actos emitidos por los órganos del mismo violentan sus derechos político electorales. Para impugnar los actos del Consejo General, sus comisiones o alguna de las instancias del Instituto, podrá accederse a los medios de defensa considerados en la Ley General del Sistema de Medios de Impugnación en Materia Electoral, atendiendo las formalidades y plazos señalados en sus disposiciones. ${ }^{21}$

Queda claro que en los Lineamientos se previene de forma puntual el procedimiento a seguir, así como las atribuciones de cada órgano o área del INE involucradas en la planeación y ejecución de los actos relacionados con la organización de las elecciones de los dirigentes o dirigencias de los partidos políticos, a través del voto universal y directo de sus militantes. Dicho de otra forma, los lineamientos no rigen de manera expresa otras modalidades de elección aun si estatutariamente están previstas.

Todo proceso electivo de dirigentes partidistas debe fundamentarse, en principio, en las normas estatutarias. Como se describe en los Lineamientos, cuando el INE participe en la elección de dirigencias debe considerar que los procedimientos internos se desarrollarán con base en los lineamientos básicos que dispone el artículo 44 de la LGPP, es decir, deberá publicarse la convocatoria que otorgue certidumbre y cumpla la normativa interna, señalando, al menos: los cargos a elegir; métodos de elección; requisitos de elegibilidad; fechas de registro de candidaturas; fechas y lugar de elección. Además de las disposiciones legales y estatutarias aplicables, existen las condiciones particulares que derivan de los términos acordados entre el Instituto y los partidos políticos. Se trata de una situación diferente cuando el Instituto se compromete a una colabo-

la Revolución Democrática, con base en la suma de las actas de cómputo estatal de dicha elección, se expiden los resultados obtenidos de las elecciones señaladas y se hacen públicos por conducto de los medios impresos y electrónicos de que disponga el instituto.

${ }^{21}$ Del 1o. de julio al 1o. de septiembre de 2014 se presentaron ante el TEPJF un total de 1757 asuntos relacionados con el proceso de elección de integrantes del Consejo Nacional, consejos estatales y municipales, y Congreso Nacional del PRD. Según lo manifestado por el propio Tribunal, la totalidad de los medios de impugnación que fueron presentados se desahogaron antes del 7 de septiembre del año en curso. www.portal. te.gob.mx/noticias-opinion-y-eventos/boletin/0/262/2014 (consultada el 23 de septiembre de 2014). 
ración limitada. En ese caso, el INE no se obliga a organizar el proceso electivo pero si le corresponde vigilar su constitucionalidad y legalidad. ${ }^{22}$

\section{Aspectos sustantivos respecto a la participación del INE en los procesos de integración de los órganos directivos partidistas}

Desde la perspectiva legislativa, acompañada en la posición asumida por distintos partidos políticos, se da un paso adelante en el proceso de ofrecer más y mejores garantías a la participación ciudadana dentro de los partidos, si las decisiones cupulares se sustituyen con la apertura y aplicación de convocatorias que den lugar a la competencia interna. Para romper con la "subcultura" que imperaba en los procesos internos de elección de dirigentes, circunstancia que conduce a crisis y conflictos poselectorales, es oportuno considerar la participación de autoridades electorales en la organización de esa clase de procesos.

Haciendo referencia a una nueva etapa en la vida democrática del país, algunos partidos sostienen que por la vía institucional y legal puede irse consolidando la participación de los militantes en la elección de los órganos partidistas. Se descarta que esta clase de experiencias implique riesgo para el INE y el propio partido. De hecho, como parte de la libertad de autoorganizarse, el órgano competente de un partido puede solicitar a la autoridad electoral su colaboración en los procedimientos de selección de dirigentes partidarios.

En virtud de la libertad autoorganizativa que corresponde a los partidos políticos, la intervención de la autoridad electoral en los aspectos sustantivos relacionados con la elección de dirigentes se limita en gran medida a lo previsto en las normas estatutarias. Sin embargo, dado que

22 Prevista la colaboración del Instituto al desarrollo de solo ciertas etapas, entre el INE y el PRD se revisan los términos que regirán la organización interna de delegados partidistas. Según lo pactado en el Convenio, el INE realizará las labores de organización y capacitación, pero no el registro de candidatos. El PRD entregará al INE dos cortes de su padrón de militantes, el primero al 10 de junio de 2014, para que el Instituto insacule a los funcionarios de casilla y de inició a la capacitación, el segundo y definitivo al 6 de julio, a fin de imprimir las listas nominales para la votación. Corresponde al INE la planeación y proyección del número de casillas, así como el cómputo municipal, estatal y nacional. En el caso concreto, la emisión de la convocatoria corrió a cargo del partido interesado. Excélsior, 16 de junio de 2014, en www.excelsior.com.mx (consultada el 16 de junio de 2014). 
la libertad de autoorganización involucra el contenido esencial del derecho fundamental de asociación político-electoral, la autoridad tiene la facultad y el deber de exigir el respeto cabal a las disposiciones constitucionales y legales que rigen la vida de los partidos. En ese sentido, debe buscarse la participación efectiva de ambos géneros en la integración de los órganos directivos, pues según lo establece el artículo 3o. de la LGPP, cada partido determinará y hará públicos los criterios para asegurar las condiciones de igualdad entre géneros.

Sin estar prevista de modo expreso en los lineamientos, la paridad de género deberá ser una realidad en la integración de las dirigencias partidistas. Solo a manera de precedente, la Sala Superior del TEPJF ha sostenido que a los órganos partidistas les corresponde vigilar, prevenir y remediar aquella situación que impida la equidad de género en la selección de candidatas y candidatos a integrar los puestos de dirección. De ahí que para garantizar la debida participación equitativa de mujeres y hombres en los cargos directivos, puede ser necesario convocar a una elección extraordinaria. Acorde con lo anterior, si el INE llegar a compartir la responsabilidad de organizar un proceso de elección interna, debe velar por la paridad de género. ${ }^{23}$

Puede no ser un aspecto sustantivo, pero lo cierto es que no se precisa en la LGPP, ni en los Lineamientos, cuál es el tope en el costo de organizar un proceso interno para la elección de dirigentes partidistas. Se define que mediante el respectivo Convenio General, se establecerán los mecanismos para que los costos de organización del proceso sean con cargo a las prerrogativas del partido solicitante. Puede suponerse que el INE y el partido político buscarán aproximarse a un costo razonable, pero también es posible no llegar a ese entendimiento. Si el costo propuesto

23 El 25 de junio de 2014, en la sentencia dictada en el expediente SUP-JDC-432/2014, la Sala Superior del Tribunal Electoral del Poder Judicial de la Federación determinó que cuando un partido descuida su obligación de garantizar la efectiva participación de mujeres y hombres en la integración de los órganos directivos, al no verificar que se postulen y seleccionen suficientes candidatas para cumplir con las cuotas de género, es motivo para convocar a una elección extraordinaria a efecto de elegir el número de mujeres que sea necesario para reestablecer la equidad. Lo anterior debido a que se declaró válida la elección de consejeros nacionales del Partido Acción Nacional en el estado de Yucatán, sin haberse respetado la cuota de género a pesar de que se alegue la falta de participación de mujeres en el proceso. En otras palabras, si a la convocatoria responde un número de mujeres inferior al requerido para garantizar la equidad, el partido tiene el deber de reestablecer el proceso en tanto se asegure la integración equitativa del órgano directivo. Esta clase de responsabilidad se extiende al INE cuando decide organizar la elección de dirigentes partidistas. 
por el Instituto, ya sea en la organización del proceso de renovación o el desarrollo de alguna etapa, por obra determinada, no es aceptado por el partido interesado, será facultad del INE tomar la decisión de rechazar la solicitud. A manera de referencia, artículo 72, párrafo 2, inciso $c$, de la LGPP, el gasto de los procesos internos de selección de candidatos no podrá ser mayor del $2 \%$ del gasto ordinario establecido para el año en el cual se desarrolle el proceso interno. ${ }^{24}$

Siendo facultad de los partidos solicitar la organización de los procesos de elección de dirigentes, es el INE quien puede rechazar la solicitud si existe imposibilidad material para organizar la elección interna. A fin de profundizar un comentario previo, dispuesto en el artículo 13 de los Lineamientos, el Instituto declarará la imposibilidad material cuando la solicitud no se apegue a lo indicado en la LGIPE, en la LGPP o en los propios Lineamientos, o por cualquier otra causa fundada y motivada. Recurriendo a una interpretación sistemática, el artículo 44 de la LGIPE, párrafo 1 , inciso $j$, establece que al Consejo General del INE le corresponde velar que los partidos conduzcan sus actividades dentro de los cauces legales, de ser así, si la solicitud proviene de un órgano partidista no facultado en los estatutos para encomendar al Instituto la organización de los procesos de elección de dirigentes, debe rechazarse la petición. Por supuesto, otra causa específica para rechazar la solicitud es su presentación extemporánea. De acuerdo con la LGPP, la solicitud de apoyo debe presentarse cuatro meses antes del vencimiento del plazo para la elección del órgano de dirección que corresponda, salvo que exista controversia jurisdiccional, en cuyo caso, el partido podrá solicitar que se organice la elección fuera del plazo indicado. De no ser este supuesto, el INE podrá rechazar la solicitud, fundando y motivando el acuerdo en la extemporaneidad de la petición. Es probable también rechazarla si se presenta durante un proceso electoral, pues en la LGPP no se contempla distraer al INE de la función estatal de organizar las elecciones federales. Sólo es factible en el inter-proceso solicitar el apoyo al Instituto.

A modo comparativo, diversos sistemas jurídicos contemplan la intervención de la autoridad electoral en los procedimientos de selección de

\footnotetext{
24 Según los términos del Convenio suscrito entre el INE y el PRD para la organización del proceso interno de elección de consejeros partidistas, celebrado el 7 de septiembre de 2014, el costo total proyectado será el que resulte de la ejecución de cada una de las acciones referidas a la organización y desarrollo del proceso electivo. Si se considera la capacitación; logística; impresión, traslado y resguardo de boletas, podría ascender a más 80 millones de pesos. Excélsior, 8 de julio de 2014, disponible en www.excelsior.com. $m x$ (consultada el 8 de julio de 2014).
} 
dirigentes partidarios. En Colombia se prevé esta clase de participación cuando el método de elección de los cuadros directivos sea mediante el voto directo de sus militantes y afiliados. Por su parte, en la República Dominicana la autoridad tiene facultades para fiscalizar, por iniciativa propia o previa solicitud, las asambleas y convenciones que celebren los partidos para elegir a sus órganos directivos. Mientras que en Honduras el Tribunal Nacional de Elecciones emite la convocatoria a elecciones internas y designa a un representante ante la Comisión Nacional Electoral de cada partido político, encargada de la organización, dirección y supervisión de las elecciones internas de autoridades partidarias. ${ }^{25}$

Prever en México la participación del INE en la elección de dirigentes partidistas, pretende justificarse bajo ciertos razonamientos. Se dice que una nueva forma de colaboración entre el Instituto y los partidos, con base en la autonomía, abona a la credibilidad y legitimidad en la elección de las dirigencias. Propicia el juego limpio o fair play al interior de los partidos, favoreciendo la percepción que se tiene de ellos. Dado el carácter instrumental de la autoridad, se favorece el fortalecimiento democrático de los partidos políticos.

\section{Consideraciones finales}

Resulta mezquino no reconocer que el liderazgo actual del PRD acertó al poner en manos del INE la elección de consejeros y congresistas para designar al presidente del partido. Los dividendos de este ejercicio están a la vista. El proceso se llevó a cabo con éxito y por primera vez en muchos años el PRD libró los conflictos que se presentaban en cada sucesión interna. La participación del INE sirvió para fortalecer la convivencia democrática al interior del partido. ${ }^{26}$

A pesar de la consideración anterior, suscita algunas dudas la intervención del INE en los procesos de elección de dirigentes partidistas. Ante la existencia de múltiples corrientes de opinión dentro de un partido político, puede darse el caso de elecciones muy competidas y con resultados apretados, lo que constituye un caldo de cultivo en el que proliferan

25 Orozco Henríquez, José de Jesús, La democracia interna.., cit, p. 31.

26 Casar, María Amparo, El gobierno legítimo del PRD, Excélsior, 24 de septiembre de 2014, disponible en http://www.excelsior.com.mx/opinion/2014/09/24/983302.php (consultada el 24 de septiembre de 2014). 
las impugnaciones electorales. Bajo esa tónica puede darse el siguiente cuestionamiento: ¿en qué situación se coloca al Instituto ante la violencia poselectoral y el acomodo de corrientes internas?

Como sostienen algunos, no es buena idea involucrar al INE en la elección de los dirigentes partidistas. Las autoridades electorales deben concentrarse en la organización de los procesos para renovar a los órganos del Estado, dejando que los partidos se ocupen de su organización e integración. No es pertinente abrirle al Instituto otro frente de controversias, sobre todo cuando esta clase de inclusión no guarda relación con los motivos y propósitos que impulsaron la reforma. ${ }^{27}$ En el proceso de elección de dirigentes partidistas del PRD no fue extraño que diversas decisiones del Instituto fueran revocadas o modificadas por el TEPJF, incluso por órganos del propio partido.

Concluido el plazo conferido a las entidades federativas para armonizar su legislación electoral con la de índole federal, sobre el tema motivo de estudio, algunas legislaciones, como la del Estado de México, facultan al Organismo Público Local Electoral para organizar la elección de dirigentes de los partidos políticos con registro estatal. Es de suponerse que los Lineamientos aprobados por el INE serán una referencia razonable.

\section{Bibliografía}

Castillo González, Leonel, Los derechos de la militancia partidista y la jurisdicción, México, Tribunal Electoral del Poder Judicial de la Federación, 2004.

Freidenberg, Flavia, "Democracia interna: reto ineludible de los partidos políticos”, Revista de Derecho Electoral, San José, Costa Rica, núm. 1, primer semestre de 2006.

González Oropeza, Manuel y Báez Silva, Carlos, La intervención de los órganos electorales del Estado en la vida interna de los partidos políticos, México, UNAM, Instituto de Investigaciones Jurídicas, 2010.

Instituto Federal Electoral, Observaciones a la minuta de reforma política de la Consejera María Marván y los Consejeros Electorales Marco Antonio Baños, Lorenzo Córdova y Benito Nacif presentada a la opinión pública y las Cámara de Diputados y Senadores el pasado 5 de diciembre

\footnotetext{
27 Idem.
} 
2013, Coordinación Nacional de Comunicación Social, núm. 157-A, en $h t t p: / /$ ife.org. $m x /$ portal/site/ifev2/menuitem.92.

Maitret Hernández, Armando, Democracia interna de los partidos. Obligación de todo órgano partidista a dar respuesta a los militantes, México, Serie Comentarios a las sentencias del Tribunal Electoral, núm. 25, Tribunal Electoral del Poder Judicial de la Federación, 2010.

Orozco Henríquez, José de Jesús, La democracia interna de los partidos políticos en Iberoamérica y su garantía jurisdiccional, México, Colección de Cuadernos de Divulgación sobre aspectos doctrinarios de la Justicia Electoral, núm. 7, Tribunal Electoral del Poder Judicial de la Federación, 2004.

Woldenberg, José, "Vida interna de los partidos políticos y fiscalización de los recursos, nuevos retos de la autoridad electoral", Democracia interna y fiscalización. Memoria del IV Congreso Nacional de Tribunales y Salas Estatales Electorales, México, Tribunal Estatal Electoral de Michoacán, 2002.

\section{Hemerografía}

CASAR, María Amparo, “El gobierno legítimo del PRD”, Excélsior, 24 de septiembre de 2014, en http://www.excelsior.com.mx/opinion/2014/ 09/24/983302.php.

Peschard, Jacqueline, "Mayor injerencia de los Estados en los partidos políticos", El Universal, 12 de mayo de 2014, en http://www.eluniver salmas.com.mx/editoriales/2014/05/68501.php.

Excélsior, 16 de junio de 2014, en www.excelsior.com.mx.

\section{Documentos oficiales}

Acuerdo del Consejo General del Instituto Nacional Electoral por el que se dictamina la posibilidad material para organizar la elección nacional de integrantes del Consejo Nacional, Consejos Estatales y Municipales y Congreso Nacional del Partido de la Revolución Democrática. INE/CG86/2014.

Acuerdo de la Junta General Ejecutiva del Instituto Nacional Electoral por el que se aprueban los resultados obtenidos de los cómputos totales correspondientes a las elecciones de integrantes del Consejo Nacional y Congreso Nacional del Partido de la Revolución Democrática. INE/JGE57/2014 
Convenio de Colaboración suscrito entre el Instituto Nacional Electoral y el Partido de la Revolución Democrática, por medio del cual se establecen las bases de cooperación en la organización y desarrollo del proceso interno para la elección nacional de integrantes del Consejo Nacional, Consejos Estatales y Municipales, mediante el voto secreto y directo de todos los afiliados. Aprobado mediante Acuerdo INE/ CG86/2014, de fecha 2 de julio de 2014.

Tribunal Electoral del Poder Judicial de la Federación, Expediente SUPJDC-781/2002.

Tribunal Electoral del Poder Judicial de la Federación, Expediente SUPRAP-033/2000.

Tribunal Electoral del Poder Judicial de la Federación, Expediente SUPJDC-1728/2006.

Tribunal Electoral del Poder Judicial de la Federación. Jurisprudencia y Tesis Relevantes 1997-2005. Compilación Oficial.

Tribunal Electoral del Poder Judicial de la Federación, Expediente SUPJDC-432/2014.

Tribunal Electoral del Poder Judicial de la Federación. La Sala Superior del TEPJF resuelve la totalidad de juicios por elecciones internas en el PRD. Boletín de prensa, martes 23 de septiembre de 2014,www.portal. te.gob.mx/noticias-opinion-y-eventos/boletin/0/262/2014.

\section{Legislación y lineamientos}

Ley General de Instituciones y Procedimientos Electorales.

Ley General de Partidos Políticos.

Lineamientos del Instituto Federal Electoral para la Organización de las Elecciones de los Dirigentes o Dirigencias de los Partidos Políticos Nacionales a través del Voto Universal y Directo de sus Militantes. 
Esta revista forma parte del acervo de la Biblioteca Jurídica Virtual del Instituto de Investigaciones Jurídicas de la UNAM www.juridicas.unam. $\mathrm{mx}$ 


\section{Normas editoriales}

Solo se publicarán trabajos originales e inéditos. El idioma oficial de la revista es el español. Los artículos que estén escritos en inglés, francés, italiano o portugués se publicarán en esos mismos idiomas. Se consideran inéditos aquellos que ya hayan sido publicados en los anteriores $\mathrm{u}$ otros idiomas y se traduzcan por primera vez al español.

Los trabajos deberán entregarse impresos y en versión electrónica. Los primeros deberán estar impresos en láser, escritos a doble espacio, con tamaño de letra 12 puntos y capturados en el procesador de textos Word for Windows. Los segundos deberán enviarse por correo electrónico a rmde@unam.mx o revistaelectoraldelaunam@gmail.com, indicando en todo tiempo cuándo fue enviada la versión impresa.

La extensión de los trabajos no podrá ser mayor a 30 páginas tratándose de artículos; 20 páginas en coyuntura, gestión electoral, estudios legislativos y jurisprudenciales, y 10 páginas en el caso de reseñas bibliográficas.

Cada trabajo deberá ir acompañado de lo siguiente: $a$ ) un resumen en el idioma en que se presenta de no más de 200 palabras; $b$ ) un resumen en inglés de no más de 200 palabras: $c$ ) la traducción al inglés del título; d) las palabras clave que identifiquen el contenido del artículo en el idioma original y en inglés; $e$ ) una síntesis curricular del autor no mayor a 65 palabras.

De no cumplirse con alguno de estos aspectos, el trabajo se recibirá como incompleto.

Además deberá acompañarse de una carta compromiso indicando que dicho material no ha sido enviado a otra institución para su publicación.

En la elaboración de citas se sugiere utilizar la siguiente presentación:

1 Astudillo, César y Córdova Vianello, Lorenzo, Los árbitros de las elecciones estatales. Una radiografía de su arquitectura institucional, México, Instituto Electoral y de Participación Ciudadana del Estado de Jalisco-UNAM, Instituto de Investigaciones Jurídicas, 2010, p. 205.

2 González Oropeza, Manuel, "El Tribunal Electoral y la forma republicana de gobierno", Justicia Electoral. Revista del Tribunal Electoral del Poder Judicial de la Federación, México, Cuarta Época, vol. I, núm. 7, 2011, pp. 62-65. 
3 Astudillo, César y Córdova Vianello, Lorenzo, op. cit., pp. 151 y 152.

4 Ibidem, p. 154.

5 Idem.

En todo lo no previsto, se aplicarán los Lineamientos y criterios del proceso editorial del Instituto de Investigaciones Jurídicas, los cuales pueden ser consultados en la siguiente dirección electrónica: $h t t p: / / w w w . j u r i d i$ cas.unam.mx/publica/critedit/critedit.pdf.

A todo trabajo deberá adjuntarse una hoja por separado con la dirección del autor, con el propósito de mantener correspondencia con él; de igual manera se deberá indicar la institución donde labora, su cargo académico y, en su caso, teléfono, fax y correo electrónico.

Todo material que cumpla con los criterios editoriales del Instituto de Investigaciones Jurídicas será sometido a dictamen. Los dictámenes fundamentarán debidamente si el artículo es susceptible de publicación, con o sin correcciones, o bien, si se rechaza. En caso de que se sugieran cambios, el autor tendrá dos semanas para realizar los cambios necesarios. Una vez que se acepte un trabajo, los autores deberán ceder el derecho de autor al Instituto de Investigaciones Jurídicas.

A cada autor se le enviarán dos ejemplares.

Revista Mexicana de Derecho Electoral, núm. 6, juliodiciembre de 2014, es una publicación semestral editada por el Instituto de Investigaciones Jurídicas de la UNAM. Se terminó de imprimir el 3 de agosto de 2015 en los talleres de Arte Gráfico y Sonoro, Agys Alevin, S. C., Retorno de Amores 14-102, colonia Del Valle, delegación Benito Juárez, 03100 México, D. F., tel. 5523 1151. En su edición se empleó tipo Minion Pro de 11.5, 10.5 y 9 puntos, y Corbel de 16, 11.5, 9, 8 y 7.5 puntos. Se utilizó papel cultural $70 \times 95$ de 50 kilos para los interiores y couché de 250 gramos para los forros.

Consta de 80 ejemplares (impresión digital).

Queda estrictamente prohibida la reproducción total o parcial de los contenidos e imágenes de la publicación sin previa autorización del Instituto Nacional del Derecho de Autor. 